Preprint

\title{
X-ray Optics Research for Linac Coherent Light Source: Interaction of Ultra-short X-ray Pulses with Matter
}

J. Kuba, A. Wootton, W. M. Bionta, R. Shepherd, E. E. Fill, J. Dunn, R. F. Smith, T. Ditmire, G. Dyer, R. A. London, V. N. Shlyaptsev, S. Bajt, M. D. Feit, R. Levesque, M. McKernan, R. H. Conant

U.S. Department of Energy This article was submitted to

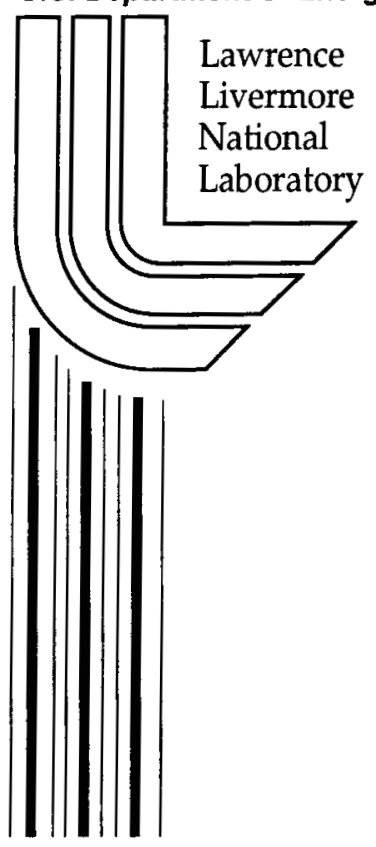

$8^{\text {th }}$ International Conference of X-ray Lasers, Aspen, CO, May 27-31, 2002

April 16, 2003 


\section{DISCLAIMER}

This document was prepared as an account of work sponsored by an agency of the United States Government. Neither the United States Government nor the University of California nor any of their employees, makes any warranty, express or implied, or assumes any legal liability or responsibility for the accuracy, completeness, or usefulness of any information, apparatus, product, or process disclosed, or represents that its use would not infringe privately owned rights. Reference herein to any specific commercial product, process, or service by trade name, trademark, manufacturer, or otherwise, does not necessarily constitute or imply its endorsement, recommendation, or favoring by the United States Government or the University of California. The views and opinions of authors expressed herein do not necessarily state or reflect those of the United States Government or the University of California, and shall not be used for advertising or product endorsement purposes.

This is a preprint of a paper intended for publication in a journal or proceedings. Since changes may be made before publication, this preprint is made available with the understanding that it will not be cited or reproduced without the permission of the author.

This work was performed under the auspices of the United States Department of Energy by the University of California, Lawrence Livermore National Laboratory under contract No. W-7405-Eng-48.

This report has been reproduced directly from the best available copy.

Available electronically at http://www.doc.gov/bridge

Available for a processing fee to U.S. Department of Energy And its contractors in paper from

U.S. Department of Energy Office of Scientific and Technical Information

P.O. Box 62

Oak Ridge, TN 37831-0062

Telephone: (865) 576-8401

Facsimile: (865) 576-5728

E-mail: reports@adonis.osti.gov

Available for the sale to the public from

U.S. Department of Commerce

National Technical Information Service 5285 Port Royal Road Springfield, VA 22161

Telephone: (800) 553-6847

Facsimile: (703) 605-6900

E-mail: orders@ntis.fedworld.gov

Online ordering: http://www.ntis.gov/ordering.htm

OR

Lawrence Livermore National Laboratory Technical Information Department's Digital Library

http://www.llnl.gov/tid/Library.html 


\title{
X-ray Optics Research for Linac Coherent Light Source: Interaction of Ultra-short X-ray Pulses with Matter
}

\author{
Jaroslav Kuba*, Alan Wootton, Richard M. Bionta, Ronnie Shepherd, \\ Ernst E. Fill ${ }^{1}$, James Dunn, Raymond F. Smith, Todd Ditmire ${ }^{2}$, \\ Gilliss Dyer ${ }^{2}$, Richard A. London, Vyacheslav N. Shlyaptsev, \\ Sasa Bajt, Michael D. Feit, Rick Levesque, \\ Mark McKernan and Ronald H. Conant \\ Lawrence Livermore National Laboratory, 7000 East Ave, Livermore, CA 94550, USA \\ ${ }^{I}$ Max-Planck Institut für Quantenoptik, D-85748 Garching, Germany \\ ${ }^{2}$ Department of Physics, The University of Texas at Austin, Austin, TX 78712, USA
}

\begin{abstract}
Free electron lasers operating in the 0.1 to $1.5 \mathrm{~nm}$ wavelength range have been proposed for the Stanford Linear Accelerator Center (USA) and DESY (Germany). The unprecedented brightness and associated fluence predicted for pulses $<300 \mathrm{fs}$ pose new challenges for optical components. A criterion for optical component design is required, implying an understanding of $\mathrm{x}$-ray - matter interactions at these extreme conditions. In our experimental effort, the extreme conditions are simulated by currently available sources ranging from optical lasers, through $x$-ray lasers (at $14.7 \mathrm{~nm})$ down to $\mathrm{K}$-alpha sources $(\sim 0.15 \mathrm{~nm})$. In this paper we present an overview of our research program, including (a) Results from the experimental campaign at a short pulse (100 fs -5 ps) power laser at $800 \mathrm{~nm}$, (b) $\mathrm{K}-\alpha$ experiments, and (c) Computer modeling and experimental project using a tabletop high brightness ps $\mathrm{x}$-ray laser at the Lawrence Livermore National Laboratory.
\end{abstract}

\section{INTRODUCTION}

The development of modern high power laser facilities in XUV regime brings new opportunities for the research of basic physical processes involved in the X-ray matter interaction. In turn, it also poses new challenges on optical components. For example, at the Linac Coherent Light Source (USA), the projected brightness and associated non-focused fluence (up to $30 \mathrm{~J} \mathrm{~cm}^{-2}$ ) in $<300 \mathrm{fs}$ will be available in 2008 and, at the TESLA source (DESY, Germany), the focused intensities of $10^{19} \mathrm{~W} / \mathrm{cm}^{2}$ in $100 \mathrm{fs}$ pulses will be achievable in 2011.

\footnotetext{
•E-mail: kuba1@Ilnl.gov
} 


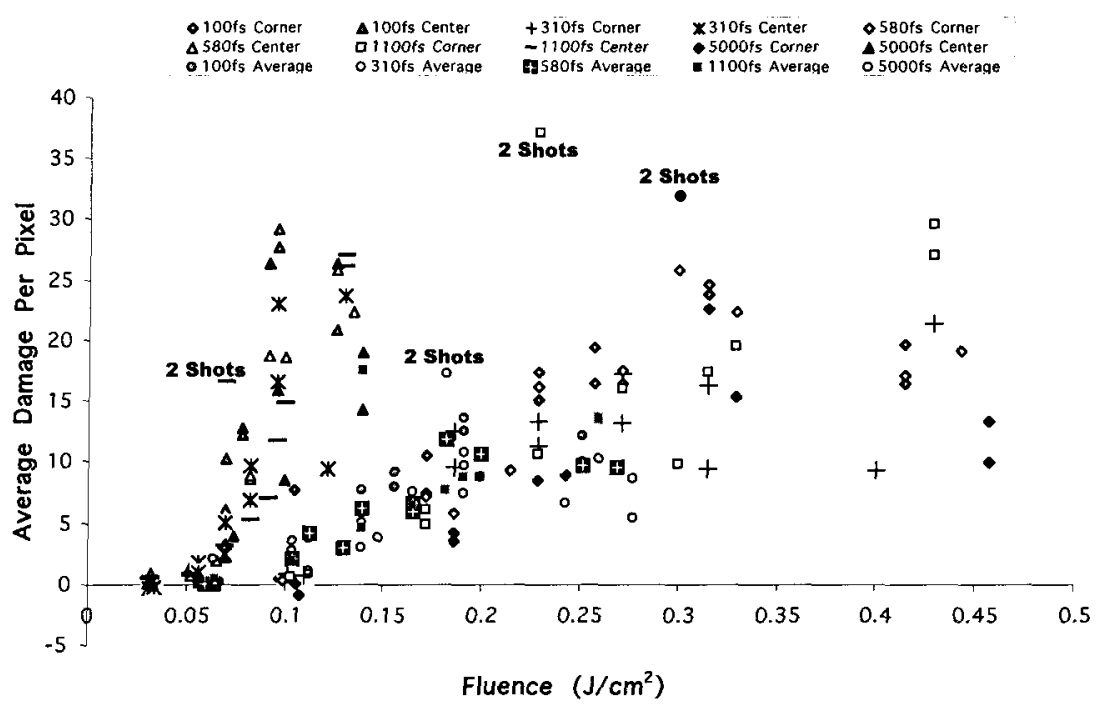

FIGURE 1. Irreversible damage at fluences as low as $\sim 0.1 \mathrm{~J} \mathrm{~cm}^{-2}$ with no dependence on pulse length was observed. High power short pulse duration laser experiment at $800 \mathrm{~nm}$ was carried out in 2001 .

Interaction experiments have been performed at many laser facilities, e.g. [1-4] in the (near-) visible wavelength range or in the XUV range [5] using a quasi-steadystate long pulse $X$-ray laser (XRL) at the NOVA and Janus facilities. At the LLNL the research involves the interaction of $x$-ray pulses with various materials from sources available nowadays with the aim to simulate the expected parameters of the 4th generation x-ray sources. In this paper we present our results, numerical modeling and experimental projects on the three major paths being pursued at the LLNL.

\section{EXPERIMENTS AND SIMULATIONS A. Damage by 800-nm Laser Pulses}

Surrogate experiments using infrared pulses provided by the USP facility at the LLNL were carried out in 2001. A single Si crystal (111) was irradiated by $800-\mathrm{nm}$ converging beam laser pulses under normal incidence, with the footprint defined by a $1 \mathrm{~mm} \times 1 \mathrm{~mm}$ aperture. The sample was placed $5.5 \mathrm{~cm}$ beyond the aperture. The footprint on the sample was measured to be $0.321 \times 0.359 \mathrm{~mm}$. Both incident and reflected energies were measured, allowing the absorbed energy to be deduced. The measured reflectivity was $0.12 \pm 0.06$. Pulse lengths were varied between 100 fs and $5000 \mathrm{fs}$, with fluences up to $\sim 0.3 \mathrm{~J} \mathrm{~cm}^{-2}$.

After irradiation the samples were examined by an optical microscope. White light was reflected at normal incidence off the Si wafer, and the resulting pictures recorded at each spot heated by the laser. Presumably, the darker areas in the pictures correspond either to increased white light absorption, or to areas where the white 
scattering has been out of the microscope objective, in either case due to surface damage.

For each pixel in the image a background value representative of no damage was subtracted. Furthermore, the images were numerically corrected for the Fresnel diffraction pattern on the square aperture. Where obvious extraneous darkening appears (e.g. striations running diagonally across the wafer) the data was excluded from the analysis. Three values were taken for each picture: (a) an average darkening across each area inspected (i.e. across the $0.0156 \mathrm{~mm}^{2}$ ), (b) in the central region, and (c) in the four areas of maximum irradiation due to the diffraction.

The data (Fig. 1) show clearly observable irreversible damage at fluences as low as $\sim 0.1 \mathrm{~J} \mathrm{~cm}^{-2}$, with no dependence on intensity (the pulse duration was varied by a factor of more that 100 while keeping the energy constant; the damage onset fluence remained unchanged). Recently, a German group has repeated our experiment and found the same results [6]. This onset fluence is 50 times lower than that predicted from the linear absorption coefficient $\left(800 \mathrm{~cm}^{-1}\right)$ assuming the threshold damage process is melting of the surface. We infer that an additional absorption mechanism must be operating for these rather intense pulses.

Experiments at $625 \mathrm{~nm} \mathrm{[3]} \mathrm{see} \mathrm{a} \mathrm{melting} \mathrm{threshold} \mathrm{of} 0.17 \mathrm{~J} \mathrm{~cm}^{-2}$, similar to ours, which they attribute to 2-photon absorption. However, at $800 \mathrm{~nm}$, the 2-photon energy is below the direct band gap for $\mathrm{Si}$ and therefore the absorption coefficient is expected to be fairly small [7]. Furthermore, we observe that the damage fluence is insensitive to pulse length, arguing against 2- or multiphoton processes. It is possible that the enhancement is due to free-free absorption. In this case, linear absorption seeds an avalanche breakdown, which generates sufficient free electrons to increase the strength of the free-free absorption coefficient. This is similar to the multi-photon seeded avalanche breakdown inferred in ultra-short pulse interaction with fused silica [8].

R. London, S. Rubenchik, and M. Feit of the LLNL are currently developing a theoretical model.

\section{B. K- $\alpha$ source Interaction with Matter}

The second type of $\mathrm{x}$-ray - matter interaction experiments involves the use of a $\mathrm{K}-\alpha$ source generated by a short $(\sim 100 \mathrm{fs})$ laser pulse. The target materials range from $\mathrm{Cu}(8.0 \mathrm{keV})$ to $\mathrm{Al}(1.5 \mathrm{keV})$. The projected experiment will use such a $\mathrm{K}-\alpha$ source to irradiate (in back-emission) a sample material (Fig. 2). The advantages of this scheme consist in a short wavelength comparable with the projected X-FEL facilities, and short pulse duration achievable. The scheme, however, requires basic research to produce reliable and well-described K- $\alpha$ sources.

Preliminary experiments at the ATLAS 10 (Max-Planck-Institut, Germany) facility were carried out in order to develop and characterize various $\mathrm{K}-\alpha$ sources. The ATLAS 10 laser facility delivered typically 200-600 mJ (on-target energy) in 130-fs pulses at $10-\mathrm{Hz}$ repetition rate or in a single pulse mode. The beam was focused by an off-axis parabola to a minimum of $9.4-\mu \mathrm{m}$-in-dimeter spot on a solid target [50-75 $\mu \mathrm{m}$ 
by $4 \mathrm{~cm} \times 4 \mathrm{~cm}$ ] supported by an aluminum substrate. Copper, iron, and titanium targets were irradiated with P-polarized laser light at a 45 deg angle of incidence. The intensity on target was controlled by varying the target position to change the focal spot size. The best focus position was optimized by the Hartman plate method. The resulting intensities on target and spot size were measured after the original experiment using a Coherent LaserCam CCD camera with the help of SPIRICON Laser Beam Diagnostics software. The measurement showed that the maximum irradiation intensities were around $2 \times 10^{18} \mathrm{~W} / \mathrm{cm}^{2}$.

The resulting spectra were diagnosed by a $512 \times 512,16$-bit, $12.3 \times 12.3-\mathrm{mm}$ Photometrics CCD under an angle of $\sim 45$ degrees. The CCD irradiation was reduced by transmission filters ( $5 \mu \mathrm{m}$ of $\mathrm{Ti}$ and $10 \mu \mathrm{m}$ of $\mathrm{Ni})$. The $\mathrm{K}$-alpha source vertical dimension was measured by means of a knife-edge input horizontally into the emission in front of the $\mathrm{CCD}(\sim 7 \mathrm{~cm}$ away from the target $)$.

In the first part of the experiment, the $\mathrm{Cu} \mathrm{K}$-alpha measurements reproduced well the results obtained during previous experiments by Eder et al. [9]. The optimization with respect to the focal spot yielded the maximum K-alpha emission of $3.7 \times 10^{9}$ photons/sterrad (supposing an isotropic emission in this angle). Our maximization of $\mathrm{Cu} \mathrm{K}$-alpha emission corresponds to the source diameter of $75 \mu \mathrm{m}$ (even though of a slightly oval shape due to the parabola focusing), which is consistent with $70-\mu \mathrm{m}$ diameter reported in [9].

Comparison in Fig. 3 shows the optimization of the laser intensity to maximize the $\mathrm{K}-\alpha$ output. The emission from a Ti target appears more intense than that of $\mathrm{Fe}$ or $\mathrm{Cu}$. The results suggest that the emission rises for lower $\mathrm{Z}$ number of the target (cf. also [10]). A possible explanation would be that the energy conversion (laser to K-alpha) remains similar within the observed $Z$ interval and hence only a smaller number of high energetic photons can be released in comparison with those at lower photon energy for low- $Z$ materials.

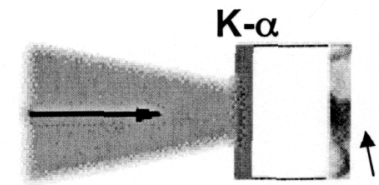

Sample

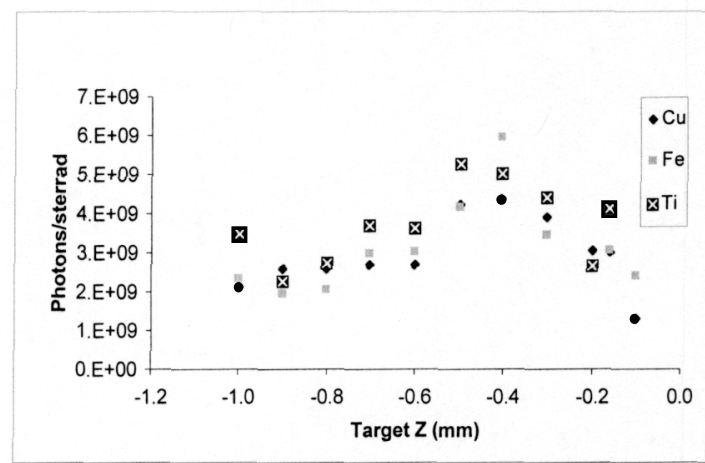

FIGURE 2. In a proposed experiment X-ray radiation from a short pulse laser driven $\mathrm{K}-\alpha$ source will interact with an investigated sample.

FIGURE 3. K- $\alpha$ source optimization with respect to the laser intensity (varied by means of defocusing the irradiation laser). 


\section{X-ray Laser Interaction with Matter}

The proposed experimental campaign will concentrate on the interaction of the focused XRL beam provided by the COMET tabletop facility [12] with multi-layer mirrors. These will include Si- and C-based optics, such as $\mathrm{Mo-Si}$ or $\mathrm{Ru}-\mathrm{C}$, operated under near-normal incidence. The damage will be studied by time-resolved measurements of the reflected beam using an ultra-fast streak camera with resolution up to $300 \mathrm{fs}$. The reflected pulse will be compared on a shot-to-shot basis with the original pulse, a small portion of which will be sent directly to the streak camera without the focusing and interaction with the target (Fig. 4). This scheme will allow us to evaluate the intensity profile on the target, and to calibrate the spot size (and hence intensity) as a function of the distance between the focusing optics and the target. The experimental work will provide data on reflectivity changes and then by interpretive modeling on material changes both during and after the x-ray pulse.

The hydrodynamic changes that affect mirror properties on intermediate to later times can be currently modeled by the LASNEX and RADEX codes [11]. Preliminary results demonstrating the high sensitivity to small material property changes are shown in Fig. 5, where dynamic photon absorption and subsequent expansion in a MoSi multilayer mirror are modeled with the code RADEX. The resulting density profiles were then input into a multilayer optics code to calculate the dynamic reflectivity, which is what will be experimentally measured. By varying the multilayer period and incident beam angle, substantial changes in reflectivity are predicted. The changes shown take place on hydrodynamic timescales and produce distinct 'signatures' in the multilayer reflectivity as a function of photon energy (or incidence angle) arising from material expansion into vacuum. Other physical effects
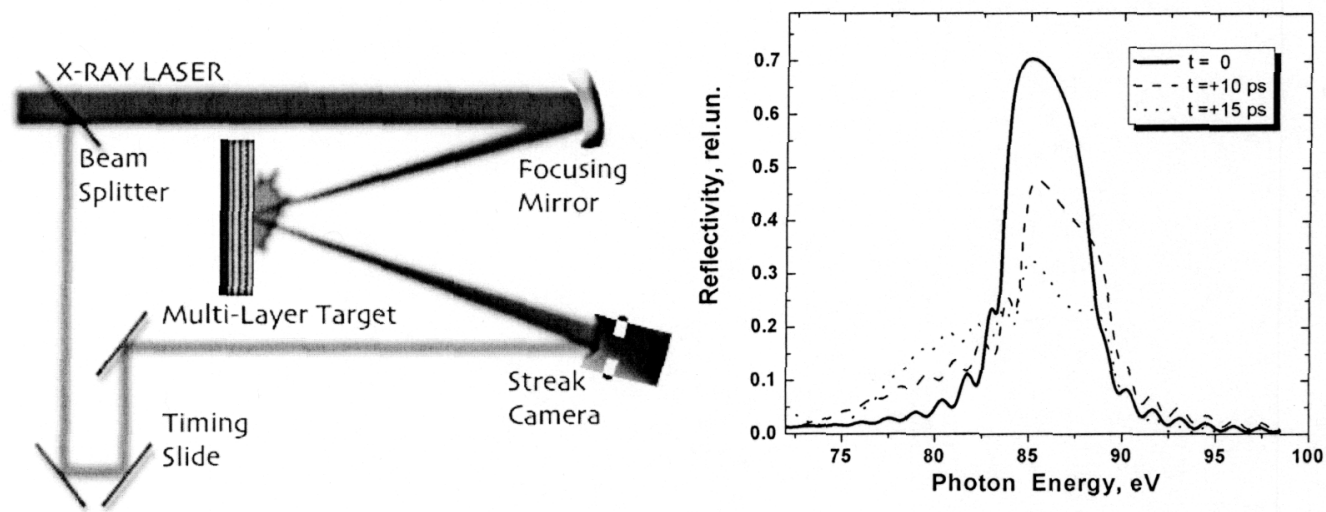

FIGURE 4. Proposed layout for an experiment on focused XRL beam interaction with multi-layer mirror samples.

FIGURE 5. Modeling of the $\mathrm{X}$-ray reflectivity of a $\mathrm{Mo} / \mathrm{Si}$ multilayer mirror under the incidence angle of 8 degrees (50 pairs, $30 \AA \mathrm{Mo} / 45 \AA \mathrm{Si}$ on a silicon substrate), where $\mathrm{t}=0$ is the beginning of the incident laser pulse: duration 5 ps at FWHM, intensity $1.710^{11} \mathrm{~W} / \mathrm{cm}^{2}$, photon energy $84 \mathrm{eV}$. 
with different timescales lead to different reflectivity temporal behavior, including changes seen only after the $x$-ray pulse is over. For example, one might find improvements in reflectivity on subsequent shots. The preliminary theoretical analysis predicts in some conditions the occurrence of phase transitions like melting on (sub-) ps timescales.

\section{CONCLUSIONS}

In this paper we presented the experimental program and associated simulations on $\mathrm{x}$-ray - matter interaction that is being carried out at the Lawrence Livermore National Laboratory. In a surrogate experiment with a short pulse ( $100 \mathrm{fs}-5 \mathrm{ps}$ ) power laser at $800 \mathrm{~nm}$ we demonstrated irreversible changes in a silicon target at fluences as low as $0.1 \mathrm{~J} \mathrm{~cm}^{-2}$, which is 50 times lower than that predicted from the linear absorption coefficient assuming the threshold damage process is melting of the surface, which suggest that other processes are involved.

In frame of the K- $\alpha$ program, we optimized K- $\alpha$ sources from different targets. In our further work the K- $\alpha$ sources will be used to investigate the interaction of a sample with this short $\mathrm{X}$-ray pulse. The experimental program will continue both at the ATLAS 10 facility in Germany and at the JanUSP facility at the LLNL.

Finally, the XRL project was presented where the focused short pulse transient XRL will interact with a multi-layer mirror target. The simulations predict substantial changes in reflectivity of this resonance system.

\section{REFERENCES}

[1] J. Larsson et al., Appl. Phys. A 66, 587 (1998)

[2] A. M. Lindenberg et al., Phys. Rev. Lett. 84, 111 (2000)

[3] K. Sokolowski-Tinten et al., Phys. Rev. B 61, 2643 (2000)

[4] D. A. Reis, Phys. Rev. Lett. 86, 3072 (2001)

[5] B. J. MacGowan et al., Journal of X-Ray Science and Technology 3 (1993) 231

[6] J. Bonse et al., Appl. Phys. A 74, (2002) 19

[7] Reitze, et al., J. Opt. Soc. Am. B 7, 84 (1990)

[8] B.C. Stuart et al, Phys. Rev. B 53, 1749 (1996)

[9] D. C. Eder, G. Pretzler, E. Fill, K. Eidmann, A. Saemann, Appl. Phys. B 70, $211(2000)$

[10] Ch. Reich, Phys. Rev. Lett. 84, 4846 (2000)

[11] Yu.V. Afanasiev, V.N. Shlyaptsev et al., J. of Sov. Laser Research 10, 1 (1989)

[12] J. Dunn et al., Phys. Rev. Lett. 84, 4834 (2000)

This work was performed under the auspices of the U.S. Department of Energy by the University of California, Lawrence Livermore National Laboratory under contract No. W-7405-Eng-48. 